\title{
On the creation of networks and knowledge
}

Citation for published version (APA):

Cowan, R., Jonard, N., \& Zimmermann, J-B. (2004). On the creation of networks and knowledge. MERIT, Maastricht Economic Research Institute on Innovation and Technology. MERIT-Infonomics Research Memorandum Series No. 010 https://doi.org/10.26481/umamer.2004010

Document status and date:

Published: 01/01/2004

DOI:

10.26481/umamer.2004010

Document Version:

Publisher's PDF, also known as Version of record

\section{Please check the document version of this publication:}

- A submitted manuscript is the version of the article upon submission and before peer-review. There can be important differences between the submitted version and the official published version of record.

People interested in the research are advised to contact the author for the final version of the publication, or visit the DOI to the publisher's website.

- The final author version and the galley proof are versions of the publication after peer review.

- The final published version features the final layout of the paper including the volume, issue and page numbers.

Link to publication

\footnotetext{
General rights rights.

- You may freely distribute the URL identifying the publication in the public portal. please follow below link for the End User Agreement:

www.umlib.nl/taverne-license

Take down policy

If you believe that this document breaches copyright please contact us at:

repository@maastrichtuniversity.nl

providing details and we will investigate your claim.
}

Copyright and moral rights for the publications made accessible in the public portal are retained by the authors and/or other copyright owners and it is a condition of accessing publications that users recognise and abide by the legal requirements associated with these

- Users may download and print one copy of any publication from the public portal for the purpose of private study or research.

- You may not further distribute the material or use it for any profit-making activity or commercial gain

If the publication is distributed under the terms of Article $25 \mathrm{fa}$ of the Dutch Copyright Act, indicated by the "Taverne" license above, 


\section{MERIT-Infonomics Research Memorandum series}

On the Creation of Networks and Knowledge

Robin Cowan, Nicolas Jonard \& Jean-Benoît Zimmermann

2004-010

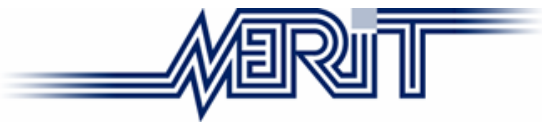

MERIT - Maastricht Economic Research Institute on Innovation and Technology

PO Box 616

6200 MD Maastricht

The Netherlands

$\mathrm{T}:+31433883875$

F: +31433884905

http://www.merit.unimaas.nl

e-mail:secr-merit@merit.unimaas.nl

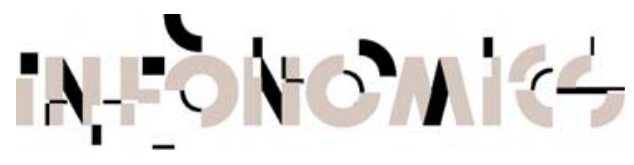

International Institute of Infonomics

c/o Maastricht University

PO Box 616

6200 MD Maastricht

The Netherlands

$\mathrm{T}:+31433883875$

F: +31453884905

http://www.infonomics.nl

e-mail: secr@infonomics.nl 


\title{
On the Creation of Networks and Knowledge*
}

\author{
Robin Cowan ${ }^{\dagger}$ Nicolas Jonard ${ }^{\ddagger}$ and Jean-Benoit Zimmermann ${ }^{\S}$
}

\begin{abstract}
This paper examines the evolution of networks when innovation takes place as a result of agents bringing together their knowledge endowments. Agents freely form pairs creating a globally stable matching. paired agents combine their existing knowledge to create new knowledge. We study the properties of the dynamic network formed by these interactions, and the resultant knowledge dynamics. Each agent carries an amount of knowledge of a certain type, and the innovative output of a pair is a function of the partners' endowments and types. We find evidence that the pattern of substitution between quantity and type of knowledge in the innovation function is vital in determining the growth of knowledge, the emergence of expertise and the stability of a number of network structures. Network structure itself exhibits a phase change when the relative importance of diversity compared to quantity increases beyond a threshold value.

Keywords: Knowledge, Networks, Innovation, Stable Matching, Small Worlds.
\end{abstract}

\footnotetext{
${ }^{*}$ Part of this research was done while Jonard was a visiting scholar at the International Institute on Infonomics, and we thank that institute for its support. We also thank the French Embassy in Canada for having supported this research through a grant from the France-Canada research fund.

$\dagger^{\dagger}$ MERIT, Maastricht University.

$\ddagger$ CNRS, BETA, Université Louis Pasteur.

$\S$ CNRS, GREQAM, Université Aix-Marseille II.
} 


\section{Introduction}

This paper is concerned with three issues: knowledge creation; knowledge diffusion, and the creation and evolution of networks.

In recent years many empirical studies of the creation of knowledge argue that innovation is to a very great extent the recombination of existing knowledge. ${ }^{1}$ At the same time, economists have observed that the knowledge base underlying a firms productive and innovative activities has broadened. That is, to operate competitively, or to innovate effectively a firm has to have access to more and more types of knowledge. A strategy that firms now commonly employ to address these to problems is for form alliances with other firms for the purpose of producing knowledge. ${ }^{2}$

To model diffusion economists first turned to epidemiology, and adapted the epidemic model of diffusion. Populations mix, any agent being equally likely to contact any other, and innovations spread by "infected agents" contacting "uninfected agents". ${ }^{3}$ More recently, however, economists have observed that this sort of global mixing does not describe well the way knowledge or information is passed among agents. Economists now recognize that much knowledge transmission takes place in bilateral or small multi-lateral interactions. ${ }^{4}$ If this is generally the case, then the nature and structure of these interactions will be central in determining the speed and extent of diffusion in an economy. Thus, to study diffusion will involve studying the networks over which the diffusion takes place. There are growing numbers of network models in economics now, but many of them take the network structure as fixed, and even if agents have many interactions, they are all with the same small subset of the population. This is reasonable in many instances, but a more general approach, wherein the network is allowed to evolve over time would be more general, since an agent will typically change the set of agents with whom he interacts as he gains experience about where the highest rents lie.

The literature contains models in which networks evolve. ${ }^{5}$ This literature tends to have an equilibrium approach, with rational agents whose actions produce a static equilibrium, in which the network structures that emerge tend to be driven by the costs of form ing links. There is a small contrasting literature that is more evolutionary in spirit. ${ }^{6}$ In this literature agents learn about the value of interacting with other agents over time, and the network evolves, typically through some form of reinforcement learning. The present paper includes features of both approaches. In this paper we treat networks as evolving as

\footnotetext{
${ }^{1}$ See for example Kodama (1986,1992); Gibbons et al. (1994); Sutton and Hargadon (1996) or Hargadon and Sutton (1997).

${ }^{2}$ See for example Zimmermann (1995); Cowan and van de Paal (2000). Smith (2000); Hagedoorn (2001) or Antonelli (1999).

${ }^{3}$ See for example Griliches (1957) or Mansfield (1961).

${ }^{4}$ See for example David and Foray (1992); Valente (1995); Steyer and Zimmermann (1998); or Cowan and Jonard (1999 and 2000).

${ }^{5}$ See for example Debreu (1969); Haller (1994); Qin (1996); Bala and Goyal (1998, 2000) (1997). For a recent survey of the game theoretic work, see Jackson and Dutta (2001).

${ }^{6}$ see for example Plouraboué et al. (1998); or Weisbuch et al.
} 
agents interact with each other, changing their own and each other's characteristics and consequently changing partners as time passes. In the model we develop here, firms form alliances in order to create knowledge, and in so doing, transmit knowledge between them. Firms can change partners, and this is the mechanism that provides the global diffusion of knowledge. In modelling partner choice we use the stable Marriage Matching algorithm of Gale and Shapley (1962), but because agents characteristics change as a result of these partnerships, the network can continually evolve. Thus this model lies between the pure search for Nash equilibria of evolutionary game theory and the melioration models of social network dynamics.

In this paper we develop a model in which each period every firm in the population seeks a partner for knowledge creation. We restrict attention to bilateral partnerships. Firms come together and pool their existing knowledge to create new knowledge which they then both absorb. Partnerships last for one period exactly, at the end of which each firm seeks a new partnership, possibly with the previous partner. That firms search for (possibly) new partners each period implies that over time a network of knowledge flows can form, as firms create links with several different firms. The central question in this paper has to do with the structural properties of these networks and whether the properties change under different knowledge production technologies.

When innovation is the outcome of agents' pairwise interactions, rational agents will seek partners to maximize the expected outcome of the partnership. Put another way, at each period of time, an agent will rank each of his potential partners on the basis of the expected benefits from that interaction. The issue then is to divide the population into $n / 2$ pairs such that each agent's partner is the best he can have, given everyone else's preferences. This is known as the room-mate problem. In general stable matches are not guaranteed in the room mate problem, but as we show below in our model they are. This implies that in every period the network of paris that forms is stable in a Nash sense.

\section{The model}

Innovation and pair formation take place in parallel. Regarding innovation, individuals' knowledge is combined to produce new knowledge. A production function encompassing both agents' amounts and types of knowledge determines how much new knowledge is generated. Agents rank each other depending on the expected output of a partnership. Hence rankings change over time because innovation changes individual knowledge profiles. Two broad categories of issues are examined: the process of network formation; and the properties of knowledge growth. 


\subsection{Knowledge and matching}

Consider a finite set $S=\{1, \ldots, n\}$ of individuals engaged in repeated interactions. Each individual $i \in S$ is characterized by a real-valued knowledge endowment, $v_{i}$, in the form of a quantity of knowledge $\rho_{i}>0$ and a composite index representing a type of knowledge $\theta \in(0, \pi / 2): v_{i}=\left(\rho_{i}, \theta_{i}\right.$. This allows a very simple polar representation of individuals, as well as the existence of a continuum of knowledge types. Individual knowledge level and type are randomly drawn from a uniform distribution over $(0,1) \times(0, \pi / 2)$ at the beginning of the process. At each period, agents seek partners with whom to innovate, after which knowledge is absorbed and agents start again a round of matching, based on their new knowledge profiles.

Innovation then, is a process that combines the knowledge of two agents and produces new knowledge. In this process, all else equal, more knowledge will be better. But diversity of knowledge inputs may also matter. Two agents whose expertise lies in exactly the same field are likely not to find many synergies. Thus in general diversity is beneficial to the innovative process, and enters positively into the production function. To fix ideas we model this as a constant returns Cobb-Douglas function, the arguments being the lengths of the knowledge vectors of the two agents (how knowledgeable they are), and the extent to which their expertise differs, that is, the difference between their knowledge "angles". The extent to which diversity matters is a parameter we vary as the exponent on the "difference in angles" argument in the Cobb-Douglas function.

\subsection{Knowledge and innovation}

There are many ways to characterize knowledge, none of them without its pitfalls. For our purposes two aspects of knowledge are important-quantity and type. Recent views of innovation as recombination make it imperative that any formal characterization of knowledge permit that equally knowledgeable agents may know different things. That is, the knowledge of an agent comprises many different types of knowledge. One approach then would be to formalize knowledge as a long vector, each element representing a different type of knowledge. Agents differ then along many dimensions. This proves cumbersome in implementation however, and is more detailed than necessary for the issues we are exploring here. A simplification of this approach is to represent an agent's knowledge as a pair: one element signifying a quantity of knowledge; the other signifying a type. This representation has the drawback that it takes what is clearly a complex thing, an agent's knowledge stock, and represents it as a pair. But it has the great benefit of simplicity; it is easily generalized; and does capture some important elements of the nature of knowledge.

A representation of the innovation process must satisfy several minimal requirements. Consider two individuals $i$ and $j$ with knowledge stocks $\left(\rho_{i}, \theta_{i}\right)$ and $\left(\rho_{j}, \theta_{j}\right)$ respectively. Suppose they are paired in a stable matching. As innovation is jointly conducted, after innovation has taken place, the following should 
be true:

- the knowledge amounts held by $i$ and $j$ have increased;

- the knowledge types of $i$ and $j$ have changed;

- the distance between the knowledge types of $i$ and $j$ has fallen.

In a geometric sense, both vectors are longer after the innovative episode, and the angle between them has decreased. A fourth assumption is necessary for the description of innovation to be complete:

- most often, innovation produces knowledge of a type which is "between" the types of the two contributors; however, innovation sometimes produces very different knowledge.

Operationally, each pair of agents creates an amount of new knowledge determined by the production function, and this amount is simply added to their existing knowledge endowments. The type of knowledge determined is a random variable $\widetilde{\theta}$ distributed according to a truncated normal, with mean, $\bar{\theta}=\left(\theta_{i}+\theta_{j}\right) / 2$ and standard deviation $s$. The knowledge type of an individual is modified by innovation and becomes a weighted mean of his previous knowledge type and the type of new knowledge generated by innovation. This accounts for the relative importance of old and new knowledge in an individual's knowledge stock.

The standard deviation of $\widetilde{\theta}$ is a parameter we vary. If a technological system is deeply entrenched in a trajectory, we would expect the standard deviation to be small. On the other hand, in a case in which there is wide scope for technological discovery in many areas, the standard deviation of this distribution would be large. The smaller the standard deviation the more likely the new knowledge will lie "between" the knowledge of the partners. Varying this parameter permits us to explore the dynamics of these different situations.

Formally, the innovation function is $r: S^{2} \rightarrow \mathbb{R}_{+}$, with

$$
r(i, j)=\left|\theta_{i}-\theta_{j}\right|^{\beta}\left(\rho_{i} \rho_{j}\right)^{1-\beta}, \beta \in(0,1) .
$$

Parameter $\beta$ measures the importance of diversity in knowledge types in the innovative process. Individual $i$ 's new knowledge endowment is simply $\rho_{i}(t+1)=$ $\rho_{i}(t)+r(i, j)$, and given the innovation is in type $\widetilde{\theta}$-knowledge, $i$ 's new knowledge type is

$$
\theta_{i}(t+1)=\frac{\rho_{i}(t)}{\rho_{i}(t+1)} \theta_{i}(t)+\frac{r(i, j)}{\rho_{i}(t+1)} \widetilde{\theta},
$$

the weighted mean of his previous knowledge type and the new knowledge type, where the weights are the relative amounts of knowledge involved. 


\subsection{The knowledge dynamics}

Each period pairs are formed, innovation takes place and endowments change. At the end of the period the partnership is dissolved. This process is repeated, and we investigate the long run behaviour of the system. In principle knowledge vectors grow in length indefinitely, but types of knowledge are bounded between 0 and $\pi / 2$. Eventually, in the creation of knowledge, only amounts matter as that argument will dominate in the production function. This is clearly unreasonable. To solve this problem we re-normalize every period so that the population average knowledge vector has length one. What this implies is that data on aggregate knowledge levels have no meaning. However, we can still reasonably measure growth rates, and variance in knowledge levels across agents. In examining knowledge, two issues are of concern: its growth and its distribution. and allocation of knowledge in this economy. The economy's knowledge growth rate is simply the growth rate of the average knowledge level per period. It will be evaluated along the simulation horizon. Since the mean level of knowledge is by definition 1 , the variance of knowledge levels $\sigma^{2}=\frac{1}{n} \sum_{i} \rho_{i}^{2}-1$ provides a good measure of the equality of the distribution.

\subsection{Network dynamics}

A relational network exists in this economy, but in a dynamic rather than a static sense. To study its properties, we focus on the frequency of contacts (in practice, the frequency of meetings over 2,000 rounds). $G\left(S, V_{t}\right)$ is the graph associated with the stable matching achieved at time $t=0,1,2, \ldots$, that is $V_{t}(i, j)=1$ if $(i, j) \in \Gamma_{t}$ and $V_{t}(i, j)=0$ otherwise. The weighted graph recording past interactions is denoted $G(S, W)$, where $W(i, j)=W(j, i)$ is the frequency of activation of the connection between $i$ and $j$ over the final $\ell$ periods. For this graph several quantities are of interest. We study the frequency distribution of collaborations and, following Watts and Strogatz (1998), two structural parameters: the average path length and the average cliquishness. ${ }^{7}$

The value associated to a path between $i$ and $j$ is the product of the interaction frequencies along that path. The length of the shortest path (or distance) between any pair of individuals is the number of interactions in the path having largest value. Formally, defining $d(i, j)$ as the distance or length of the shortest path between $i$ and $j$, the average path length is

$$
L=\frac{1}{n} \sum_{i} \sum_{j \neq i} \frac{d(i, j)}{n-1}
$$

and simply measures how distant vertices are on average, which is a global property of the graph. Average cliquishness $C$ is a measure of local connectivity

\footnotetext{
${ }^{7}$ If one thinks of social networks representing friendship, both have int uitive interpretations. The path length is the number of friendships in the shortest chain connecting two agents. Cliquishness reflects the extent to which the friends of one agent are also friends of each other.
} 
capturing the share of active links between any given vertex's neighbours. It is written

$$
C=\frac{1}{n} \sum_{i} \sum_{j, l \in W(i)} \frac{W(j, l)}{n_{i}\left(n_{i}-1\right) / 2},
$$

where $n_{i}=\#\{j \mid d(i, j)=1\}$ is the size of $i$ 's neighbourhood. These statistics give a reasonably complete description of the structural properties of the underlying network. We add one simple measure, namely the average degree of the graph $D=\frac{1}{n} \sum_{i} n_{i}$, as a measure of the density of the interaction structure.

\section{Existence: Stable matching}

Before turning to the emergence of network structure and the associated knowledge dynamics, we discuss the matching mechanism present in this model. Because any pair of agents assigns the same cardinal value to their match, a unique stable match always exists. We can prove this proposition by construction.

Proposition 1 For any innovation function $r: S^{2} \rightarrow \mathbb{R}_{+}$generating a strict preference ordering $\succ$, the matching problem $(S, \succ)$ has a unique stable matching $\mu$.

Proof The algorithm to construct the stable matching is as follows. Let $S_{0}=S$ and $\mu_{0}=\{\varnothing\}$. Consider the roommate matching problem $\left(S_{0}, \succ\right)$, where the profile of preference orderings $\succ$ is defined by the innovation function $r$, as stated in equation (??). As preferences are strict, there is a single pair $\left(a_{1}, b_{1}\right)$ such that $r\left(a_{1}, b_{1}\right)=\max _{(i, j) \in S_{0}^{2}, i \neq j} r(i, j)$. No matching which does not involve this pair could be stable, as $a_{1}$ and $b_{1}$ both prefer each other to any other person they might be matched with. Hence the pair $\left(a_{1}, b_{1}\right)$ is necessarily part of a stable matching. Let $\mu_{1}=\mu_{0}+\left(a_{1}, b_{1}\right)$ and $S_{1}=S_{0}-\left\{a_{1}, b_{1}\right\}$. Consider then the new matching problem $\left(S_{1}, \succ\right)$. It only involves $n-2$ individuals with exactly the same preferences (modulo those concerning $a_{1}$ and $b_{1}$ ) as before this operation. Again there is a single pair $\left(a_{2}, b_{2}\right)$ such that $r\left(a_{2}, b_{2}\right)=\max _{(i, j) \in S_{1}^{2}, i \neq j} r(i, j)$. Let then $\mu_{2}=\mu_{1}+\left(a_{2}, b_{2}\right)$ and $S_{2}=S_{1}-\left\{a_{2}, b_{2}\right\}$. Repeat until everyone belongs to a pair: the set $\mu \equiv \mu_{n / 2}$ is a stable matching as no pair can blockade it, and it is unique as the sequence $\left(a_{1}, b_{1}\right),\left(a_{2}, b_{2}\right), \ldots,\left(a_{n / 2}, b_{n / 2}\right)$ is uniquely defined.

In case of a tie (that is to say when individual $i$ can achieve the same innovative output with two or more different partners), existence is still guaranteed but uniqueness is lost. The elimination algorithm to find a stable matching is unchanged, except that when two (or more than two) pairs achieve the same output, one of them is picked up randomly and the procedure just iterates. 


\section{Numerical analysis}

There are in the model two parameters that could affect the evolution of the network structure: $s$, the standard deviation of the distribution from which the angle of innovation is drawn; and $\beta$, the value of diversity in knowledge production. In the experiments that follow we simply examine two representative values for $s$, running each experiment twice, once for high and once for low $s$. The effects of $\beta$ we examine in more detail. Random values of $\beta$ are drawn from a uniform distribution over $(0,1)$. For each $\beta$ value $n=100$ individuals repeatedly interact over a horizon of length 3,000 periods. We build a data sample of 100 different $\beta$-values and two $s$-values and the associated statistics. We extract the underlying structure from these data using non-parametric estimation techniques.

\subsection{Network dynamics}

The emergence of network structure can be described using three indicators: local order or cliquishness; path lengths; and density or degree of the graph. We examine the effects of two parameters, $\beta$, a measure of the importance of diversity in innovation, and $s$, which measures the extent to which new knowledge lies between the expertise of the innovators. In the discussion that follows, we restrict ourselves to the $0 / 1$ graph. Analyzing the weighted graph, using the measures discussed above creates a problem of interpretation, since the measures are not bounded. Graphically, however, the patterns are identical to those produced by analysing the $0 / 1$ graph.

\subsubsection{Density}

Figure 1 plots the relationship between density, as measured by the average degree, and $\beta$ for two values of $s, s=0.1$ (focussed trajectory) and $s=3$ (diversified trajectory).

What we observe is that there is a phase change in the structure of the graph for $\beta^{*} \approx 0.4$. When $\beta \leq \beta^{*}$ the degree is very low. This implies that agents in general have had very few partners over history, and have tended to interact repeatedly with the same partners. For $\beta>\beta^{*}$, the network is very different. Agents interact with many different partners over time, no longer sticking to the same ones. It is worth mentioning that for small values of $\beta$ (for both values of $s$ ) and for $\beta$ close to 0.25 in the case $s=0.1$, the degree can be significantly larger than 1 although not systematically. This suggests a small region (roughly speaking for $0.2<\beta<0.4$ ) where two types of regimes can exist: a world of pairs (degree equal to one) and a more complex world of degree above 1 and below 15 , depending on the path taken by the process. After $\beta^{*}$ by contrast there is only one regime with degree around 50. Also note that when $\beta$ is further increased after 0.75 , the degree tends to decline when innovation is very localized (small $s$ ), while it remains constant when innovation is less focussed (large $s$ ). 


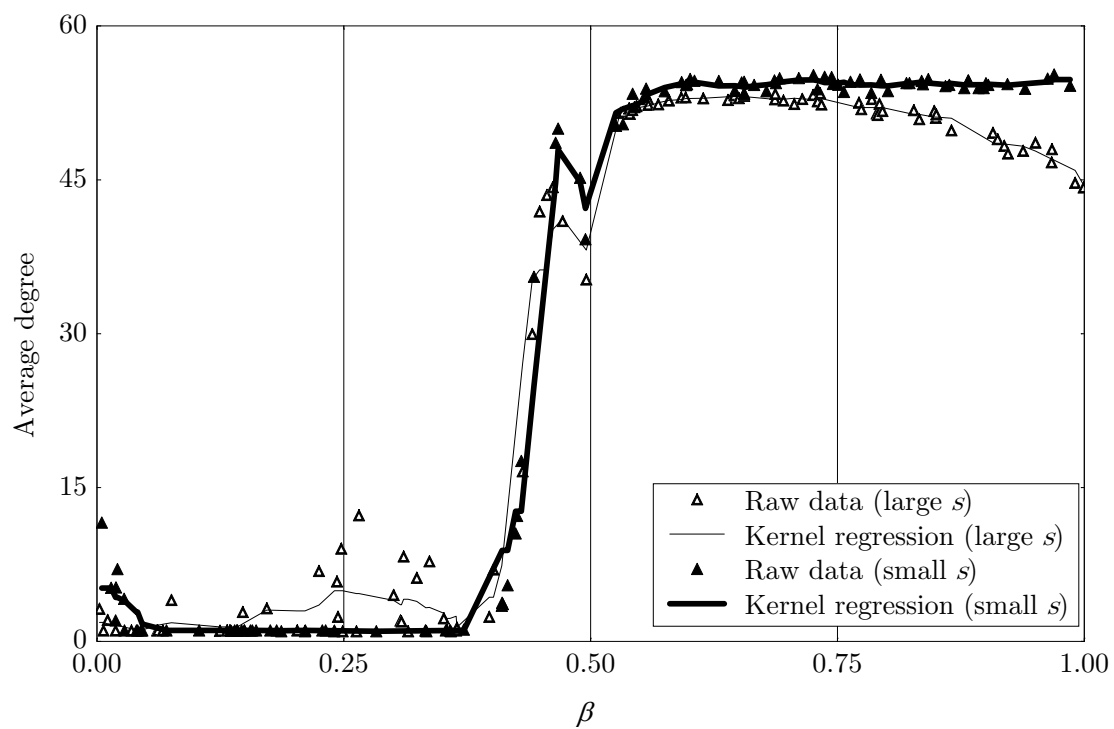

Figure 1: Average number of connections per individual

In Figure 2 we depict the number of individuals involved only in pairs that are stable over time, i.e., of individuals having a unique life-long innovation partner.

The phase change that exists for the degree is also present when the number of paired individuals is considered, with a sharp decline from a large number (between 96 and 100) below $\beta^{*}$ to 0 for $\beta>\beta^{*}$. There is also some noise in the region $[0.2,0.4]$, with a number of paired individuals that doesn't follow a clear pattern, a phenomenon similar to what we observed for the degree on Figure 1. Above $\beta^{*}$ persistent pairs do not form. Interestingly, for very small $\beta$ and a diversified innovative trajectory (large $s$ ), no pairs form and, as we will see when the path length is considered, we even get a connected graph.

\subsubsection{Path Length}

We see in Figure 3 the same phase change, at the same value of $\beta^{*}$ in average path length as in the density graph.

For $\beta<\beta^{*}$, the graph is disconnected. That is, there are isolated groups of agents who interact within groups but not across groups. In principle, this makes the average path length infinite. ${ }^{8}$ To keep the figure informative, we only

\footnotetext{
${ }^{8}$ Recall that average path length refers to the average path length between pairs of nodes in the graph. If there is no path between two agents, this creates an infinitely long path between them, making the average path infinite. In our calculation of path length, two disconnected agents have a path length of 10,000 rather than infinity. This makes the calculation possible.
} 


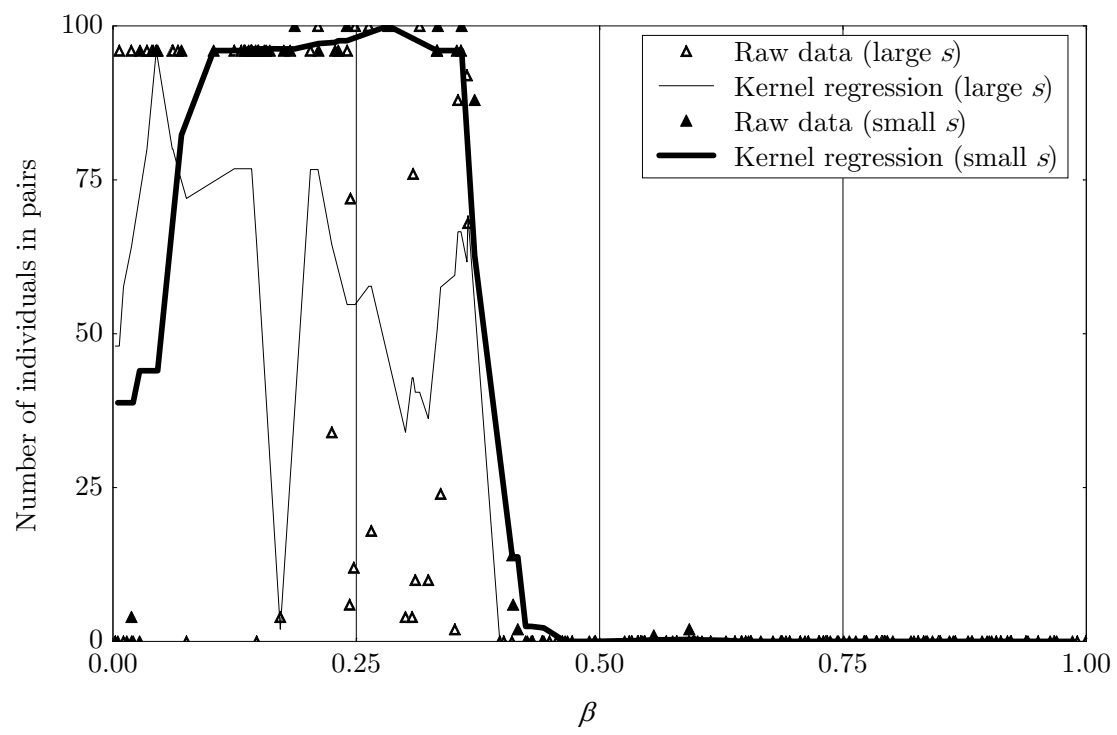

Figure 2: Number of individuals involved in pairs

consider a small range over the $y$-interval so between 0 and $\beta^{*}$ most of the points are invisible. When $\beta>\beta^{*}$, path length is very small. The lowest possible path length is 1 , and exists only in a complete graph. The networks we obtain are thus not complete (their degree is below 55, and a complete graph must have degree 99 in our case) but do have relatively short paths. What this implies is that knowledge flows relatively rapidly around the graph, and indirect exploitation of distant knowledge, through successive rounds of innovation, can be an active feature of the economy. It is known that for a fixed density, random graphs have very short average path lengths. The formula (which is valid for infinite size graphs) for the average path length over a random graph with $n$ vertices and average degree $d$ is $\ln (n) / \ln (d)$. In Figure 3 we represent the path length of the equivalent random graph (that is the random graph with 100 vertices and a degree a given in Figure 1). The path length in our case is consistently above the path length of the equivalent random graph. The networks that emerge from our dynamic process are not random, but do have path lengths approaching those of a random graph of the same degree. Interestingly, and related to the previous paragraph, it is worth mentioning that in a diversified trajectory (and to a smaller extent in a focussed one) there are situations with low $\beta(\beta \approx 0)$ in which path length is finite (between 2 and 7 in the figure). 


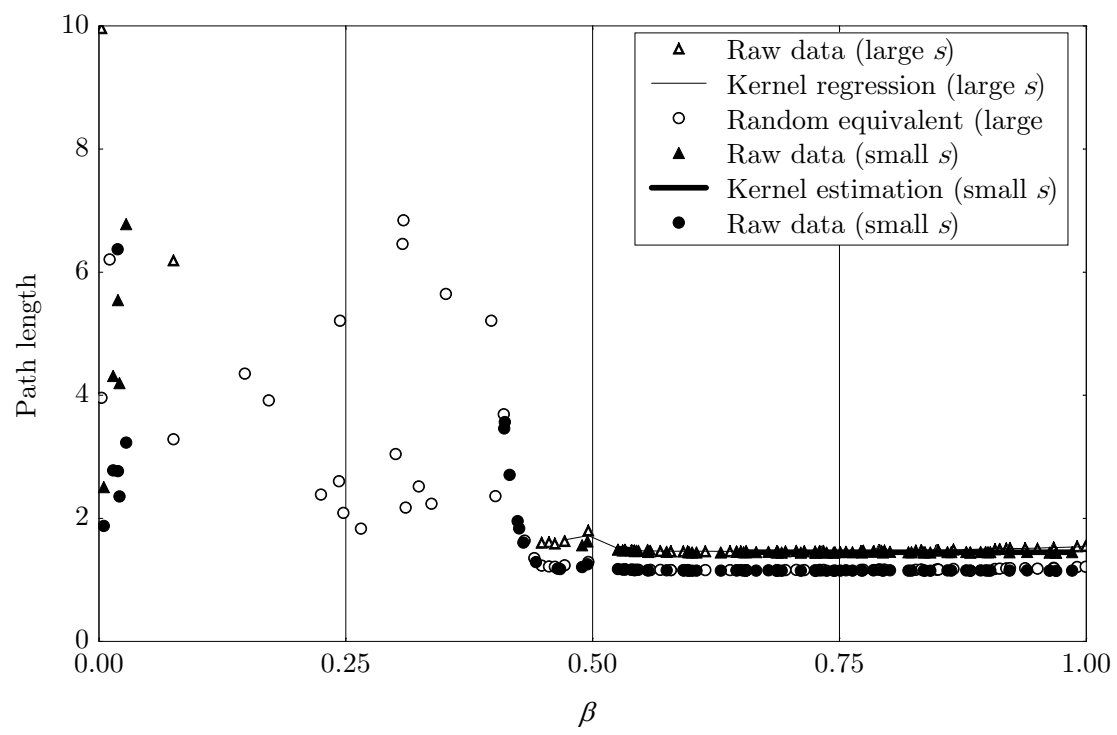

Figure 3: Average path length between any pair of individuals

\subsubsection{Local Order and Network Structures}

To describe local order we use the standard measure of cliquishness: the share of my partners who are also partners of each other.

Like the previous structural measures, cliquishness shows a phase change at the same value of $\beta^{*}$. Cliquishness is not defined for a graph of disjointed pairs, so our convention is to assign a value of zero for cliquishness of a pair. At the other extreme, a complete graph has a value of 1 , and so does a collection of complete disconnected components. In figure 4 we see for small values of $\beta$ many networks with $C$ close to 0 , but most often strictly positive. Since we know that the graph is disconnected here (and thus not complete) this means that we must be observing the emergence of a "caveman graph", that is, a graph of disconnected, complete subgraphs. From figure 1 it is clear that the caves are very small, since the average number of connections per agent is between 1 and 3 . When the value of the average cliquishness gets very small, is that there are many isolated pairs in the network. In this part of the parameter space "only length matters" so the two agents with the most knowledge will partner, and create the largest innovation, thus maintaining their positions as the most knowledgeable agents. Their partnerships is stable, as is the partnership of the next most knowledgeable pair, and so on. There is a small range, roughly $0.3<\beta<0.45$ in which the graph consists of several, but a falling number of, subgraphs which are themselves highly cliquish. We no longer have a caveman graph, but rather several connected, but not complete subgraphs. 


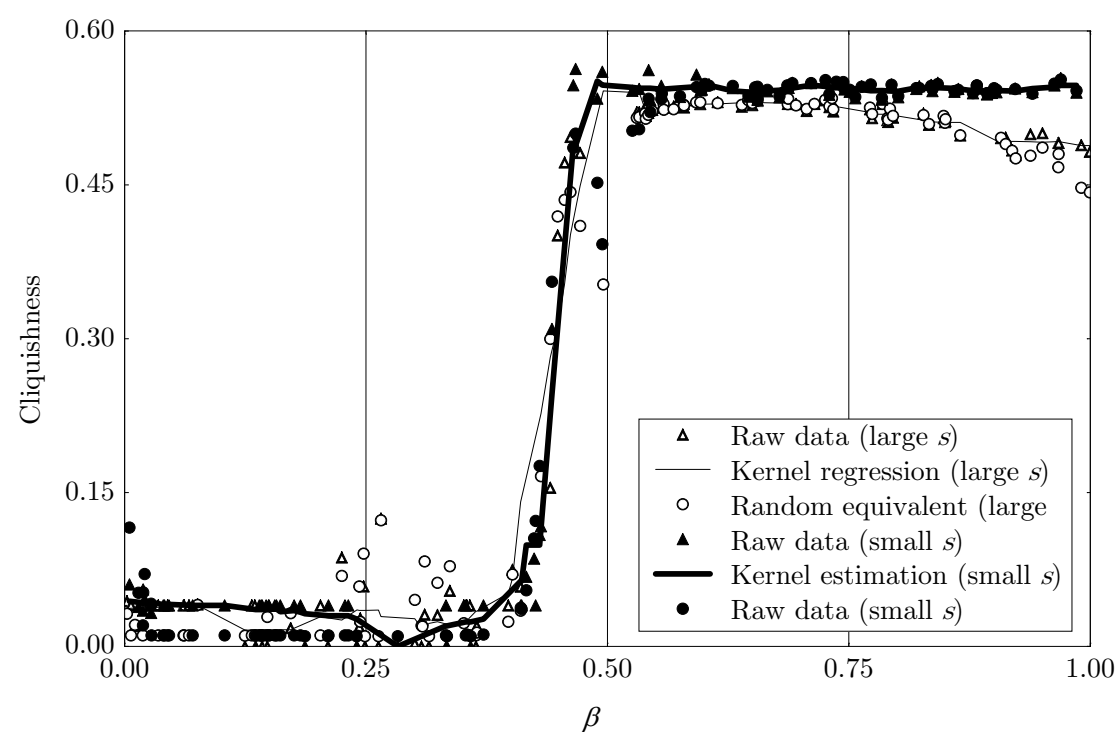

Figure 4: Average cliquishness

The cliquishness of the equivalent random graph almost perfectly tracks the observed cliquishness, whatever the value of $s$.

\subsection{Knowledge dynamics}

Figure 5 depicts the relationship between the long-run economy-wide knowledge growth rate and $\beta$.

For both values of $s$ there seem to be, again, two regimes of knowledge growth - one associated with a disconnected graph, and one with a connected graph. In both regions knowledge growth rates as diversity becomes more important. The contrast between large and small $s$ is explained by the fact that with a small value of $s$, there is a natural convergence over time in the knowledge type of the population. Since innovations tend to occur "between" the knowledge of the members of the innovating pair, knowledge types converge over time. When $\beta$ is large, diversity is important, and this convergence effect reduces growth. When $s$ is large, however, diversity is preserved over time, since there is a large variance in the type of knowledge created, so the natural convergence is mitigated by the randomness here.

Again, though, there is a small ambiguous region, for $0.25<\beta<0.4$, where there is some intermediate behaviour between that of the connected and disconnected regimes. As discussed above, in this region we see the emergence of something resembling a caveman graph - small connected (sometimes complete) sub-graphs within the disconnected total graph. Within each cave, we 


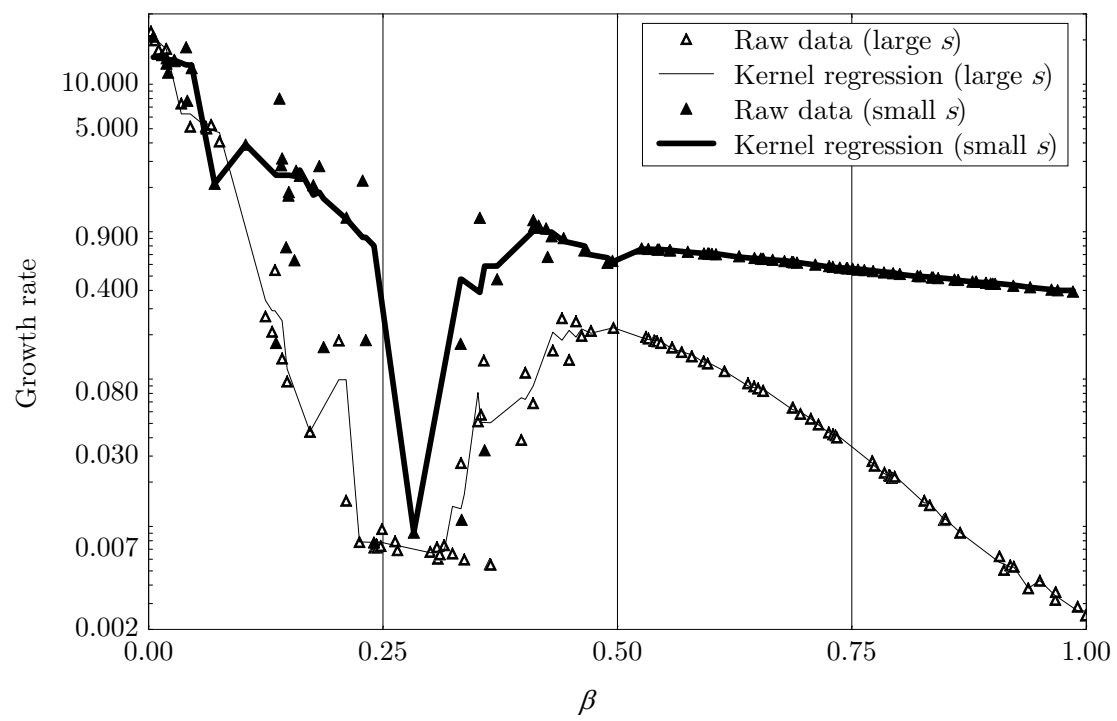

Figure 5: Growth rate of the average knowledge level

have the behaviour of a connected graph, which, holding $\beta$ constant, is good for knowledge production.

The issue of equity is addressed by considering $\gamma=\sigma / \bar{\rho}$, the coefficient of variation of individual knowledge levels. Coefficient $\gamma$ measures how dispersed around the average individual the population is, relative to this average individual. As we re-normalize at each time step, the coefficient of variation reduces to the standard deviation. Figure 6 depicts the way $\gamma$ varies with $\beta$.

For $\beta<\beta^{*}, \gamma$ is approximately equal to 7 , which corresponds to a situation in which knowledge is concentrated in the hands of exactly 2 individuals. ${ }^{9}$ There is a first fall in dispersion a bit before the critical $\beta$, and then a very marked one down to a point where under both small and large $s$ things stabilize. For small $s$ the coefficient of variation stays around 1 whereas it stabilizes in the vicinity of 0.5 for large $s$. Hence dispersion decreases with $\beta$ in a non-smooth way, and the decrease is more marked when the trajectory is more dispersed, undergoing a phase change which again is very comparable to what could be observed concerning network structure. In the beginning of the parameter space "only length matters" so the two agents with the most knowledge will partner, and create the largest innovation, thus maintaining their positions as the most knowledgeable agents. Their partnerships is stable, as is the partnership of the next most knowledgeable pair, and so on. As renormalization carries on,

\footnotetext{
${ }^{9}$ Given that we renormalize knowledge levels each period, the standard deviation is equal to 7 if and only if 98 individuals have 0 (or almost 0 ) and 2 have 50, for an average 1.
} 


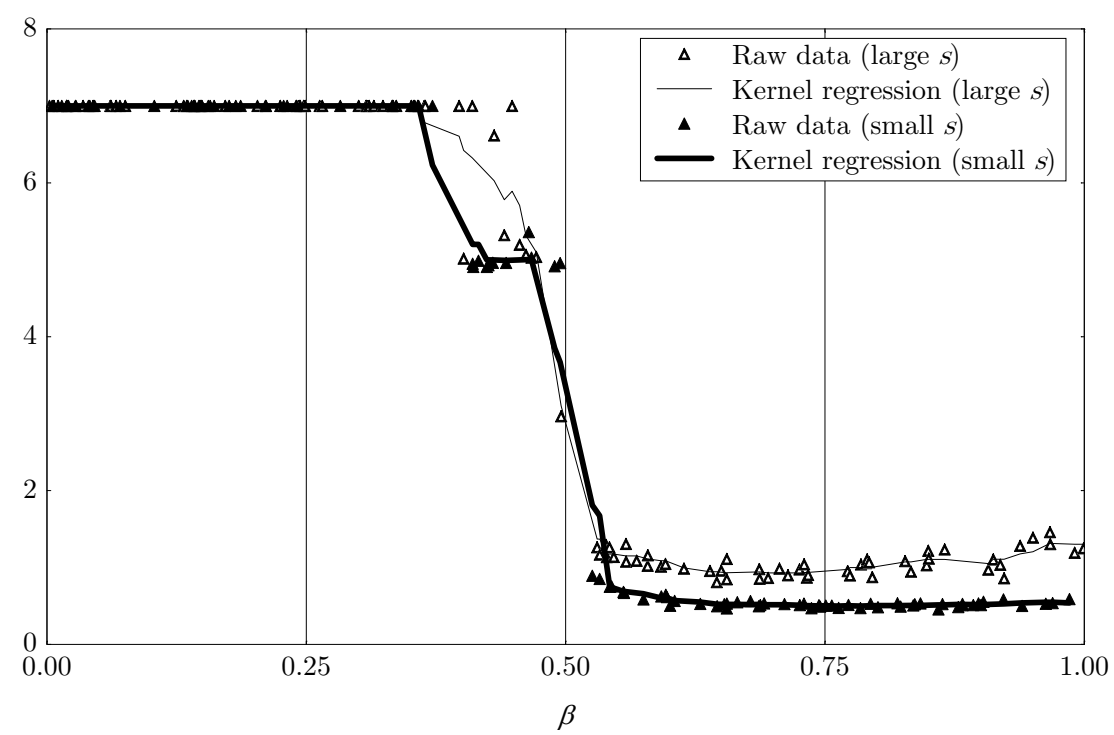

Figure 6: Coefficient of variation of individual knowledge levels

we end up with all the "renormalized" knowledge being held by the two most knowledgeable individuals. It takes a significant weight on variety to combat this tendency and to allow for pairs to fluctuate, entailing that homogeneity in terms of levels decreases. It is worth mentioning that at the other end of the parameter space, "only angle difference matters", which means that the two most distant (in angle) individuals will be matched, so will the next more different individuals, and so on. However the size of their innovation does not matter, only angles do. So with time, because innovation tends to take place "between" the knowledges of the innovating pair, there is a trend of decreasing diversity in the population, as all agents lie between the two most extreme agents of the previous period. This effect is mitigated, of course, as $s$ increases.

\section{Conclusion}

In this paper we have focussed on issues of knowledge dynamics and emerging network structures when agents create knowledge through partnership agreements. We have emphasized that knowledge creation through cooperation can be a complex process that involves pooling the competencies of the partners in different ways, depending on the nature of the innovation process. Similarly, given a pooling structure, different types of knowledge can be either substitutes or complements for each other in the innovation process itself. The former consideration is represented by the $\theta$ parameter in our model, the latter by the 
elasticity of substitution $\beta$ in a constant elasticity of substitution production function. Both parameters affect the results, both in terms of the rate of knowledge production, and in terms of the network structure. Knowledge creation is fastest when the knowledge creation production function exhibits complementarity in its inputs. The nature of knowledge pooling has no noticeable effect however. By contrast, heterogeneity among agents regarding their knowledge levels is, generally, decreasing in $\theta$. As it becomes more possible for one partner to dominate in the pooling process (or perform more of the innovation activity) heterogeneity across agents decreases.

The nature of knowledge pooling turns out to be crucial in determining the emergent structure of the network. When $\theta$ is very low, stable matchings create pairs of agents whose expertise lies in the same fields fields - agents can be seen as substituting for each other. Innovation tends to occur in that single field of expertise, and the two agents remain good partners for each other in the next round. This implies the emergence of stable pairs of agents; the network becomes a set of $n / 2$ disconnected pairs. By contrast, when $\theta$ approaches 1 , stable matchings create pairs of agents whose respective expertise lies in different fields. Innovation in this case does not reinforce existing expertise of the two agents and thus make them more similar, but rather reducing the differences between them. Thus a pair matched in this round, because they are more similar to each other after innovation are less likely to be a good match in the next round. What this implies is that pairs of agents will form and disintegrate rapidly, agents will constantly search for new partners, and the emergent network will approach a random network. With $\theta$ values between these extremes, the network structure too is between the extremes. Here knowledge pooling creates a mixture of the two agents' knowledge with each knowledge type. As $\theta$ grows from its minimum value the diameter of the stable groups or cliques increases from two. The emergent cliques tend to be relatively complete, but globally the graph remains disconnected. Cliquishness increases, and is maximal at $\theta=0.5$. For intermediate values, $0.5<\theta<1$, cliquishness falls, as the islands of communicating agents make external connections, opening themselves to each other by establishment of "shortcut" links. Global path length falls in this region and it may be that small worlds, as defined by Watts and Strogatz (1998), emerge.

\section{References}

[1] C. Antonelli. Communication and innovation : The evidence within technological districts. Presented at the International Conference "Knowledge Spillovers and the Geography of Innovation: A Comparison of National Systems of Innovation", Université Jean Monnet, Saint Etienne, France, 1999.

[2] V. Bala and S. Goyal. Learning from neighbours. Review of Economic Studies, 65:595-621, 1998. 
[3] V. Bala and S. Goyal. A non-cooperative model of network formation. Econometrica, 68:1181-1229, 2000.

[4] R. Cowan and N. Jonard. Network structure and the diffusion of knowledge. Technical Report 99028, MERIT, Maastricht University, 1999.

[5] R. Cowan and N. Jonard. The dynamics of collective invention. Technical Report 20-018, MERIT, Maastricht University, 2000.

[6] R. Cowan and G. Van de Paal. Innovation policy in a knowledge-based economy. European Commission, Enterprise Directorate-General, 2000.

[7] P. A. David and D. Foray. Markov random fields, percolation structures and the economics of document standards diffusion. Technical Report 326, CEPR, Stanford University, 1992.

[8] G. Debreu. Neighbouring economic agents. La Decision, 171:85-90, 1969.

[9] D. Gale and L. Shapley. College admissions and the stability of marriage. American Mathematical Monthly, 69:9-15, 1962.

[10] M. Gibbons, C. Limoges, H. Nowotny, S. Schartzman, and M. Scott, P. AndTroiw. The New Production of Knowledge : The Dynamics of Science and Research in Contemporary Societies. SAGE, London, 1994.

[11] Z. Griliches. Hybrid corn: An exploration in the economics of technological change. Econometrica, 25:501-522, 1957.

[12] J. Hagedoorn. Inter-firm R\&D partnerships: An overview of major trends and patterns since 1960. Research Policy, 2001. forthcoming.

[13] H. Haller. Topologies as infrastructures. In R. Gilles and P. Ruys, editors, Imperfections and Behavior in Economic Organizations. Kluwer, 1994.

[14] A. Hargadon and R. Sutton. Technology brokering and innovation in a product development firm. Administrative Science Quarterly, 42:716-749, 1997.

[15] R. Irving. An efficient algorithm for the "stable roommates" problem. Journal of Algorithms, 6:577-595, 1985.

[16] M. Jackson and B. Dutta. On the Formation of Networks and Groups. In M. Jackson and B. Dutta, editors, Models of the Strategic Formation of Networks and Groups, Springer, 2001.

[17] M. O. Jackson and A. Wolinsky. A strategic model of social and economic networks. Journal of Economic Theory, 71:44-74, 1996.

[18] D. E. Knuth. Mariages Stables. Presses Universitaires de Montréal, 1976.

[19] F. Kodama. Japanese innovation in mechatronics technology. Science and Public Policy, 13:44-51, 1986. 
[20] F. Kodama. Technology fusion and the new research and development. Harvard Business Review, 22:70-78, 1992.

[21] E. Mansfield. Intrafirm rates of diffusion of an innovation. Review of Economics and Statistics, 45:345-359, 1961.

[22] F. Plouraboue, A. Steyer, and J.-B. Zimmermann. Learning induced criticality in consumers adoption pattern: A neural network approach. Economics of Innovation and New Technology, 6:73-90, 1998.

[23] C. Qin. Endogenous formation of cooperation structures. Journal of Economic Theory, 71:218-226, 1996.

[24] K. Smith. What is the 'knowledge economy'? Knowledge-intensive industries and distributed knowledge bases. Presented to DRUID Summer Conference on "The Learning Economy - Firms, Regions and Nation Specific Institutions", June 15-17, 2000

[25] A. Steyer and J.-B. Zimmermann. On the frontier: Structural effects in a diffusion model based on influence matrixes. In P. Cohendet, P. Llerena, H. Stahn, and G. Umbhauer, editors, The Economics of Networks: Interaction and Behaviours, pages 118-135. Springer, 1998.

[26] R. Sutton and A. Hargadon. Brainstorming groups in context: Effectiveness in a product design firm. Administrative Science Quarterly, 41:685-718, 1996.

[27] T. W. Valente. Network Models of the Diffusion of Innovations. Cresskill, NJ: Hampton Press., 1995.

[28] D. Watts and S. Strogatz. Collective Dynamics of Small-World Networks., Letters to Nature, 393, May, 1998.

[29] G. Weisbuch, A. Kirman, and D. Herreiner. Market organization. In R. Conte, R. Hegselmann, and P. Terna, editors, Simulating Social Phenomena, pages 221-240. Springer, 1997. Lecture Notes in Economics and Mathematics, Volume 456.

[30] J.-B. Zimmermann. Le concept de grappes technologiques: Un cadre formel. Revue Economique, 1995. 